\title{
Description of Platelet Count Patients Infected with Corona Virus (Covid-19) with Grouping of Productive and Elderly Age
}

\author{
Hapipah $^{1}$, Anik Handajati ${ }^{2}$, Nur Vita Purwaningsih ${ }^{1}$ \\ ${ }^{1}$ Department of Medical Laboratory Technology, Muhammadiyah University of Surabaya, Indonesia \\ ${ }^{2}$ Department of Medical Laboratory Technology, Poltekkes Kemenkes Surabaya, Indonesia \\ Corresponding author: Anik Handayati (e-mail: anik_handayati@yahoo.co.id).
}

\begin{abstract}
Routine hematology tests are one of the supporting tests in diagnostics to assess the severity of the disease and predict risk in COVID-19 patients, and can be used as supporting data on RT-PCR tests. Some blood tests that are widely used as monitoring tools and predicators of COVID-19 are the number of leukocytes, the number of lymphocytes, the number of neutrophils, the number of platelets and NLR (Neutrophil lymphocyte ratio). Thrombocytopenia occurs due to excessive use of tromocytes in the body as compensation for damage to lung parenchym cells, the lungs are organs where platelets are released from megacaryocytes, so this damage causes disruption of platelet maturation process. The type of research used is quantitative descriptive with the aim to find out the results of blood tests complete with platelet parameters in patients infected with the COVID-19 coronavirus at Muhammad Noer Pamekasan General Hospital. The results of the study were platelet count test results at normal productive age of 67 respondents $(96 \%)$ and decreased platelet count (Thrombocytopenia) by 3 respondents (4\%). While in normal elderly age a number of 26 respondents $(87 \%)$ and a decreased platelet count (Thrombocytopenia) amounted to 4 respondents $(13 \%)$.
\end{abstract}

INDEX TERMS COVID-19 Positive Patients, Platelet Count, Thrombocytopenia

\section{INTRODUCTION}

Coronavirus Disease 2019 (COVID-19) is a viral infection caused by severe acute respiratory syndrome coronavirus 2 (SARS-CoV-2). SARS-CoV-2 is a zoonotic pathogen that when it was first discovered in the 1960s only causes common cold, a virus that attacks the respiratory tract that occurs mild disturbances in the respiratory system, and can occur lung infections that can cause death. In the past 20 years, two pathogenic types of coronavirus have been reported: SARS in 2003 and Middle East Respiratory Syndrome Coronavirus (MERS-CoV) in 2012. The death rate due to SARS and MERS is much higher than COVID19 , which is $10 \%$ due to SARS and $37 \%$ for MERS. However, the transmission of COVID-19 is much wider than the two diseases [1][2] [3].

The COVID-19 virus is dominantly spread when sneezing or coughing, and can also be indirectly through contaminated objects or surfaces. Transmission can occur in both systematic and asistomatic patients. The incubation

Vol. 2 No. 1, February 2022, pp:7-10 period of COVID-19 is about 2 to 14 days (average 5 days). COVID-19 patients experience the main symptoms of fever, cough, and shortness of breath. Other symptoms can be malaise, swallowing pain, nausea or vomiting, congeti breath, headache, and diarrhea. In addition, severe cases can manifest with a low to moderate fever, even without fever, during the course of the disease, which may be because older patients are more likely to suffer from severe illness and may not have a good "fever response". The incidence of probality develops into Acute Respiratory Syndrome (ARDS) [1], [4], [5].

The risk of complications in COVID-19 is higher in some vulnerable populations, susceptibility in COVID-19 is especially in the elderly, individuals who suffer from weakness, or who have chronic conditions. So far, the coronavirus has been seen as causing severe infections and deaths in the elderly than in adults and children. The elderly group becomes the group most at risk of transmission of the 
COVID-19 virus because the elderly group of the immune system that has been weakened plus the presence of chronic diseases can increase the risk of COVID-19 [6][7].

Thrombocytopenia is one of the most common reasons hematologically consulted in critically ill patients, in COVID-19 combination as a factor that can cause low platelets i.e. underlying liver problems, drug side effects, heparin-related thrombocytopenia (HIT), primary hematological disease (immune thrombocytopenia, thrombolic thrombolynic purpura, etc.), viral infections and inflammatory responses are some of many of those causes. An increase in platelet count is also seen to be associated with respiratory viral disease, secondary platelet position (ST) as a prognostic marker in viral diseases [8][9].

A decrease in platelet count $<150,000 / \mathrm{L}$ is categorized as thrombocytopenia. Abnormal platelets are often associated with viral diseases that are not specific to COVID19. Low platelet count is an important prognostic indicator of severity and mortality in COVID-19 patients. While thrombocytopenia can be associated with significant events, reactive thrombocytosis can be associated with increased hypercoagulability or and thrombogenity [10][11].

Thrombocytopenia in COVID-19 can be one of the severity predicators in patients exposed to the COVID-19 virus. Thrombocytopenia in severe diseases or patients with sepsis often occurs because it is related to physiological deempensation in the form of Disseminated Intravascular Coagulation (DIC). In the previous study showed that thrombocytopenia occurs due to excessive use of platelets in the body as compensation for damage to lung parenchym cells. In addition, the lungs are organs where platelets are released from megakaryocytes, so damage to this organ causes disruption of platelet maturation process [12] [13]. Based on the background description above, the aim of this study is to find out the results of blood tests complete with platelet parameters in patients infected with the COVID-19 at Muhammad Noer Pamekasan General Hospital with grouping of productive and elderly age.

\section{METHODS}

The type of research used is descriptive, with the aim to find out the picture of platelet count in COVID-19 patients at productive age and the elderly at Muhammad Noer Pamekasan General Hospital. The population in this study was the productive age and the elderly age who examined platelet counts in COVID-19 patients at Mohammad Noer Pamekasan General Hospital. The sample of this study was the productive age and elderly who tested positive for COVID 19 at Muhammad Noer Pamekasan General Hospital. The data was taken based on the results of examinations at the laboratory of Muhammad Noer Pamekasan General Hospital conducted during JanuaryApril 2021. The data retrieval technique in this study uses secondary data, namely taking data that has been recorded or results from the Laboratory at Mohammad Noer Pamekasan General Hospital. The study was conducted at the Mohammad Noer Pamekasan General Hospital Laboratory installation in September - June 2021. The study variable is an Description of platelet counts in COVID-19 patients at productive and elderly age at Mohammad Noer Pamekasan General Hospital. The data obtained in the study was analyzed using a descriptive approach. The results of the analysis are entered in the form of a table then tabulated and presented, in the form of $\%$.

\section{RESULTS}

\section{A. CHARACTERISTICS OF RESPONDENTS}

The sample used in this study amounted to 100 respondents with 70 respondents having a productive age and 30 elderly. Secondary data retrieval method through medical relam at Muhammad Noer Pamekasan General Hospital. Here are the results of the secondary data (TABLE $1)$ :

\section{1) DATA ON MEAN CALCULATION AND STANDARD DEVIATION IN PRODUCTIVE AND ELDERLY AGE}

TABLE 1

Data of Mean Calculation Results and Standard Deviation

\begin{tabular}{|c|c|c|}
\hline Age & \multicolumn{2}{|c|}{ Calculation Results } \\
\hline $\begin{array}{c}\text { Productive Age } \\
(15-60)\end{array}$ & MEAN & 250.500 \\
\cline { 2 - 3 } & SD & 82.250 \\
\hline $\begin{array}{c}\text { Elderly Age } \\
(60-100)\end{array}$ & MEAN & 226.500 \\
\cline { 2 - 3 } & SD & 74.750 \\
\hline
\end{tabular}

In the data collection above from 70 coronavirus patients (Covid-19) obtained an average value of platelet count at productive age of $250,500 \mathrm{~L}$, platelet values that are highest $415,000 \mathrm{~L}$ and the lowest $86,000 \mathrm{~L}$. The normal platelet count is 67 patients.

While in the data collection above from 30 coronavirus patients (Covid-19) obtained an average value of platelet count at the elderly age of $226,500 \mathrm{~L}$, the highest platelet value of 376,000 $\mathrm{L}$ and the lowest 77,000 L. The normal platelet count was 26 patients.

\section{2) Platelet COUNT ANALYSIS BASED ON AGE}

Based on TABLE 2 it is seen that out of 100 samples, as many as 70 respondents $(70 \%)$ of the sample have a productive age of 15-60 years, as many as 30 respondents $(30 \%)$ the sample has an elderly age of 60-100 years.

TABLE 2

Respondent Data Based on Productive and Elderly Age

\begin{tabular}{lcc}
\hline \multicolumn{1}{c}{ Age } & $\mathrm{n}$ & Prosentase $(\%)$ \\
\hline Productive Age (15-60) & 70 & $70 \%$ \\
Elderly Age (60-100) & 30 & $30 \%$ \\
\hline Total & 100 & $100 \%$ \\
\hline
\end{tabular}

\section{3) ANALYSIS OF PLATELET COUNT RESULTS BASED ON GENDER}

Based on TABLE 3 it is seen that out of 100 samples, as many as 55 respondents $(56 \%)$ of the sample have a MALE gender and as many as 45 respondents (44\%) of the sample have a female gender. At the productive age of 70 
respondents, 33 respondents had a female gender and as many as 37 respondents had a male gender. While at the age of 30 respondents, as many as 12 respondents had a female gender and as many as 18 respondents had a male gender.

TABLE 3

Table of platelet count results by gender

\begin{tabular}{ccc}
\hline Gander & $\mathrm{n}$ & $\%$ \\
\hline Male & 55 & $55 \%$ \\
Female & 45 & $45 \%$ \\
\hline Total & 100 & $100 \%$ \\
\hline
\end{tabular}

\section{B. DESCRIPTIVE ANALYSIS}

\section{1) PLATELET COUNT DATA AT PRODUCTIVE AGE}

After obtaining data from the results of blood tests complete with the collection of platelet count data at Muhammad Noer Pamekasan General Hospital, then the data is analyzed by percentage. Listed results as follows (TABLE 4).

TABLE 4

Platelet Count Test Results at Productive Age based on Normal and Abnormal

\begin{tabular}{cccccc}
\hline \multirow{2}{*}{ No } & \multirow{2}{*}{ Age } & \multicolumn{3}{c}{ Platelet Count Test Results } \\
\cline { 3 - 6 } & & \multicolumn{2}{c}{ Normal } & \multicolumn{2}{c}{ Abnormal } \\
\cline { 3 - 6 } & & $\mathrm{n}$ & $(\%)$ & $\mathrm{n}$ & $(\%)$ \\
\hline 1. & $\begin{array}{c}\text { Productive age } \\
(15-60)\end{array}$ & 67 & $\begin{array}{c}96 \\
\%\end{array}$ & 3 & $4 \%$ \\
\hline
\end{tabular}

Platelet Count In Covid-19 Patients Of Productive Age

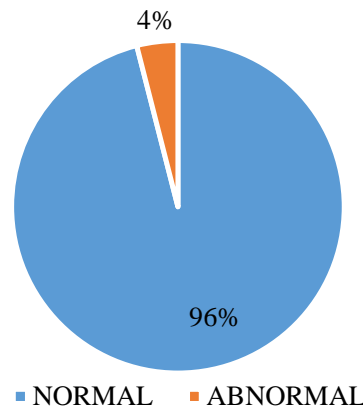

FIGURE 1. Diagram percentage of platelet count results in coronavirus patients (Covid-19) at productive age at Muhammad Noer Pamekasan General Hospital in January - April 2021.

Based on the percentage diagram as shown in FIGURE 1. It describes the results of blood tests complete with platelet count data in covid-19 patients at Muhammad Noer Pamekasan General Hospital, which is distinguished by two colors namely blue and orange, blue indicates a normal value of $96 \%$ in 67 patients while orange indicates an abnormal platelet value of $4 \%$ in 3 patients.

\section{2) PLATELET COUNT DATA AT ELDERLY AGE}

After obtaining data from the results of blood tests complete with the collection of platelet count data at
Muhammad Noer Pamekasan General Hospital, then the data is analyzed by percentage. Listed results as follows (TABLE $5)$.

TABLE 5

Platelet Count Test Results At Elderly Age based on Normal and Abnormal

\begin{tabular}{cccccc} 
& & \multicolumn{3}{c}{ Abnormal } \\
\cline { 3 - 6 } No & Age & \multicolumn{3}{c}{ Normal } & \multicolumn{2}{c}{ Abnormal } \\
\cline { 3 - 6 } & & $\mathrm{n}$ & $(\%)$ & $\mathrm{n}$ & $(\%)$ \\
\hline 1. & $\begin{array}{c}\text { Elderly age } \\
(15-60)\end{array}$ & 26 & $87 \%$ & 4 & $13 \%$ \\
\hline
\end{tabular}

Based on the percentage diagram above describes the results of blood tests complete with platelet count data in elderly covid-19 patients at Muhammad Noer Pamekasan General Hospital, which is distinguished by two colors namely blue and orange, orange indicates a normal value of $87 \%$ in 26 patients while yellow indicates abnormal platelet value of $13 \%$ in 4 patients (FIGURE 2).

Platelet Count In Covid-19 Patients At Elderly Age

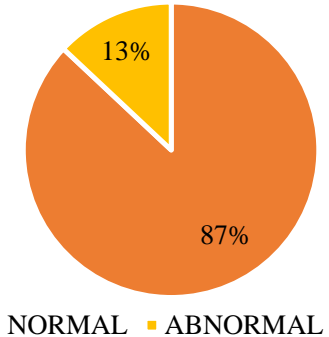

FIGURE 2. Diagram percentage of platelet count results in coronavirus patients (Covid-19) in elderly age at Muhammad Noer Pamekasan General Hospital in January - April 2021.

\section{DISCUSSION}

Research that has been conducted in January to April 2021 to obtain platelet description results on routine blood tests with patients infected with coronavirus (COVID-19) with the RT-PCR method obtained data as many as 100 respondents with 70 respondents of productive age and 30 respondents of elderly age The overall results obtained from the data are the number of platelets at the productive age with a normal value of 67 respondents and a decreased platelet count (Thrombocytopenia) number of 3 respondents. While the number of platelets in the elderly with normal values there are as many as 26 respondents and the number of platelets decreased (Thrombocytopenia) as many as 4 respondents.

COVID-19 patients who experience thrombocytopenia or decreased platelet count can be caused by several things, including the inhibition reaction of blood cell production including platelet components, increased destruction of blood cells infected with the virus, and increased apoptosis of bone dysum cells [14][15]. In addition, according to Fitriati, et.al (2020) and Lippi et.al (2020), COVID-19 
patients with severe symptoms have significant abnormalities of laboratory results namely Thrombocytopenia. Thrombocytopenia occurs in critical patients who show serious organ damage or physiological decomplenment [13][6]. In COVID-19 patients experience thrombocytopenia caused by multifactorial, such as complications from other diseases that previously existed [13].

In this study observed platelet levels in productive age and elderly. Results obtained from the laboratory test the number of platelet levels at the productive age decreased (Thrombocytopenia) by $4 \%$ while the number of platelet levels in the elderly decreased (Thrombocytopenia) by $13 \%$. This study shows the elderly are more susceptible to the occurrence of thrombocytopenia compared to productive age, it is because the elderly age is more susceptible to congenital diseases such as diabetes and hypertension [8].

Based on the results of the above study there was no significant association between platelet counts in patients infected with coronavirus (COVID-19) where in this study, there was no meaningful association between platelet counts in patients exposed to COVID-19. That is because the effect of platelet count on COVID-19 patients depends on the severity, changes in blood platelets triggered by the COVID19 virus can cause heart attacks, strokes, and other serious complications and it will be more vulnerable in patients who have a history of previous diseases. While in the grouping of age is more vulnerable at the age of the elderly than at the productive age is characterized by the productive age of the imunya system is stronger than the age of the elderly [16].

Routine hematology tests in patients suspected of being exposed to COVID-19 are very important because they can be used as test support data (RT-PCR), in addition to early detection, laboratory tests can occur COVID-19 disease travel monitoring tools. Some laboratory tests that are widely used as monitoring tools and predicators of COVID-19 are the number of lekocytes, neutrophil levels, monocyte count levels, platelet count levels and cada number of neutrophil lymphocyte ratio (NLR)

\section{CONCLUSION}

The aim of this study is to find out the results of blood tests complete with platelet parameters in patients infected with the COVID-19 at Muhammad Noer Pamekasan General Hospital with grouping of productive and elderly ageBased on the results of research on the description of routine blood test results of platelet parameters in patients confirmed COVID-19 by RT-PCR at Muhammad Noer Pamekasan General Hospital obtained the following data: The results of a study of 70 respondents at productive age and obtained an average value of 254,400 L platelet count, the results were within normal limits. The results of the study of 30 respondents at the age of the elderly and obtained an average score of 230,666 L platelet count, the results were within normal limits. In the results of the platelet count test at normal productive age amounted to 67 respondents and a decreased platelet count (Thrombocytopenia) amounted to 3 respondents. While at the age of normal elderly number of 26 respondents and the number of platelets decreased (Thrombocytopenia) amounted to 4 respondents.

\section{REFERENCES}

[1] F. Salamanna, M. Maglio, M. P. Landini, and M. Fini, "Platelet functions and activities as potential hematologic parameters related to Coronavirus Disease 2019 (Covid-19)," Platelets, vol. 31, no. 5, pp. 627-632, 2020.

[2] H. Li, B. Wang, L. Ning, Y. Luo, and S. Xiang, "Transient appearance of EDTA dependent pseudothrombocytopenia in a patient with 2019 novel coronavirus pneumonia," Platelets, vol. 31, no. 6, pp. 825-826, 2020.

[3] D. Budiman and C. Chu, "A SWOT Analysis of Indonesia's COVID-19 Pandemic Response Strategy," Int. J. Adv. Heal. Sci. Technol., vol. 1, no. 2, pp. 50-52, 2021.

[4] B. K. Manne et al., "Platelet gene expression and function in patients with COVID-19," Blood, vol. 136, no. 11, pp. 13171329, 2020.

[5] A. Rampotas and S. Pavord, "Platelet aggregates, a marker of severe COVID-19 disease," J. Clin. Pathol., vol. 74, no. 11, pp. 750-751, 2021.

[6] G. Bomhof et al., "COVID-19-associated immune thrombocytopenia," Br. J. Haematol., 2020.

[7] X. Ding et al., "Dynamic profile and clinical implications of hematological parameters in hospitalized patients with coronavirus disease 2019," Clin. Chem. Lab. Med., vol. 58, no. 8, pp. 1365-1371, 2020.

[8] D. Wang et al., "Clinical course and outcome of 107 patients infected with the novel coronavirus, SARS-CoV-2, discharged from two hospitals in Wuhan, China," Crit. Care, vol. 24, no. 1, pp. 1-9, 2020.

[9] E. Güçlü et al., "Effect of COVID-19 on platelet count and its indices," Rev. Assoc. Med. Bras., vol. 66, pp. 1122-1127, 2020.

[10] D. Giannis, I. A. Ziogas, and P. Gianni, "Coagulation disorders in coronavirus infected patients: COVID-19, SARS-CoV-1, MERS-CoV and lessons from the past," J. Clin. Virol., vol. 127, p. $104362,2020$.

[11] X. Luo et al., "Prognostic value of C-reactive protein in patients with coronavirus 2019," Clin. Infect. Dis., vol. 71, no. 16, pp. 2174-2179, 2020

[12] X. Bi et al., "Prediction of severe illness due to COVID-19 based on an analysis of initial Fibrinogen to Albumin Ratio and Platelet count," Platelets, vol. 31, no. 5, pp. 674-679, 2020.

[13] G. Lippi, M. Plebani, and B. M. Henry, "Thrombocytopenia is associated with severe coronavirus disease 2019 (COVID-19) infections: a meta-analysis," Clin. Chim. acta, vol. 506, pp. 145$148,2020$.

[14] N. Ozcelik, S. Ozyurt, B. Yilmaz Kara, A. Gumus, and U. Sahin, "The value of the platelet count and platelet indices in differentiation of COVID-19 and influenza pneumonia," J. Med. Virol., vol. 93, no. 4, pp. 2221-2226, 2021.

[15] A. Amgalan and M. Othman, "Hemostatic laboratory derangements in COVID-19 with a focus on platelet count," Platelets, vol. 31, no. 6, pp. 740-745, 2020.

[16] X. Zhao et al., "Early decrease in blood platelet count is associated with poor prognosis in COVID-19 patientsindications for predictive, preventive, and personalized medical approach," EPMA J., vol. 11, no. 2, p. 139, 2020. 